\title{
Optimization of Glucoamylase Production by Humicola grisea MTCC 352 in Solid State Fermentation
}

\author{
Vinayagam Ramesh ${ }^{1 *}$ and Vytla Ramachandra Murty ${ }^{2}$ \\ ${ }^{1}$ Department of Chemical Engineering, Manipal Institute of Technology, \\ Manipal Academy of Higher Education, Manipal 576104, Karnataka, India \\ ${ }^{2}$ Department of Biotechnology, Manipal Institute of Technology, Manipal \\ Academy of Higher Education, Manipal 576104, Karnataka, India \\ *Corresponding author.E-mail: rameshvinayagam@gmail.com \\ https://doi.org/10.12982/CMUJNS.2019.0018
}

\section{ABSTRACT}

In the industrial processing of starch, the thermostable glucoamylase is employed in saccharification step. The thermophilic fungi Humicola grisea has been used for the glucoamylase production in solid state fermentation. The extracellular glucoamylase is estimated using glucose oxidase peroxidase assay method. The initial screening studies revealed that wheat bran is the best substrate among the studied agricultural residues. The fermentation parameters were optimized through the response surface approach. By using central composite design, the optimal values of four important parameters viz., mineral salt solution concentration, incubation period, initial moisture content and inoculum size for glucoamylase production were found to be $65 \%(v / w), 80 \mathrm{~h}, 240 \%(v / w)$ and $13 \%(v / w)$ respectively. The experimental activity of $282 \mathrm{U} / \mathrm{gds}$ obtained was close to the predicted activity of $288 \mathrm{U} / \mathrm{gds}$. A high $R^{2}$ value (0.9741), $P$ values lesser than 0.05 and $A A R D$ values (1.98\%) indicate the accuracy of the proposed model.

Keywords: Glucoamylase, Humicola grisea, Response surface methodology, Solid state fermentation

\section{INTRODUCTION}

Glucoamylase (EC 3.2.1.3) is an endo-acting enzyme which cleaves both $\alpha-1,4$ and $\alpha-1,6$ linkages of starch and related polymers, capable of converting it 
completely into glucose, when incubated for longer periods (James and Lee, 1996). One of the vital process requirements for the industrial application of glucoamylase for starch processing is its use at elevated temperatures. Hence, the thermostable glucoamylase is the tool of choice in an industrial setting (Ramesh and Murty, 2014). Of the various reported glucoamylase producers, the thermophilic fungus, Humicola grisea, has been proven to be a steady source of thermostable glucoamylase (Tosi et al., 1993; Campos and Felix, 1995; Ramesh and Murty, 2015).

The conventional method of glucoamylase production employs submerged fermentation $(\mathrm{SmF})$. In the latest industrial practice, glucoamylase production is mainly carried out using solid-state fermentation (SSF) process (Anto et al., 2006). $\mathrm{SmF}$ has several disadvantages such as high capital investment, more complex process, less productivity, high water requirement and higher wastewater production, high energy requirement and high cost for downstream processing (Babu and Satyanarayana, 1995; Pandey, 2003). These issues shift the focus towards SSF process for glucoamylase production. There are dual roles played by the solid substrate used in SSF: nutrient supplement and anchorage for the fungal mycelia.

The best suited substrates for enzyme production in SSF are agricultural waste residues (Ellaiah et al., 2002). There are many agricultural waste residues such as sugarcane bagasse, wheat bran, wheat straw, rice straw, rice bran, maize bran, gram bran and oil cakes, that were successfully utilized for glucoamylase production (Ellaiah et al., 2002; Ramachandran et al., 2004; Balkan and Ertan 2007; Bhargav et al., 2008). Apart from agricultural waste residues, cereal flours, waste bread, food wastes, potato residue and tea waste have been effectively used for the production of glucoamylase (Selvakumar et al., 1998; Te Biesebeke et al., 2005; Wang et al., 2009; Lam et al., 2013; Melikoglu et al., 2013). The use of external carbon and nitrogen components along with the solid substrate enhances glucoamylase production (Kunamneni et al, 2005; Prajapati et al, 2013). Mineral salts supplementation is also necessary for glucoamylase production (Bertolin et al., 2003, Bhatti et al., 2007; Negi et al., 2011).

There are many physico-chemical factors influence glucoamylase production in SSF such as the type and concentration of solid substrate used, presence of external carbon and nitrogen source, initial moisture content $\mathrm{pH}$ of the medium, the age and size of the inoculum, fermentation temperature and duration of fermentation (Baysal et al, 2003; Ramachandran et al., 2004; Couto and Sanromán, 2006; Balkan and Ertan, 2007). Hence, it is necessary to optimize fermentation parameters after identifying the most suitable substrate to enhance glucoamylase production. The influence of the fermentation conditions on glucoamylase production has been evaluated and reported in several works. Singh and Soni (2001) optimized glucoamylase production by studying different sub- 
strates, the level and nature of moistening agent, the temperature, the presence or absence of carbon, and nitrogen and mineral supplements. Ellaiah et al., (2002) investigated some factors that influence glucoamylase production in solid state fermentation, including the initial $\mathrm{pH}$ and moisture content, the incubation time, the level of salt solution, and the effect of various substrates. Bertolin et al., (2003) investigated the effect of maltose and soluble starch on batch and fed-batch solid-state fermentation for glucoamylase production from Aspergillus awamori.

Optimization by the conventional one-variable-at-a-time approach (OVAT) is practiced by keeping all the parameters at a value, while varying a single parameter, at a time. The major disadvantage of OVAT is that it does not include the interaction effects between the variables studied. Also, the net effect of the individual medium constituents on the overall yield is not portrayed. To overcome these disadvantages, the optimization studies can be performed using statistical techniques such as response surface methodology (RSM). Kumar and Satyanarayana, (2004) and Prajapati et al., (2013) successfully applied RSM for the production of glucoamylase. In the current investigation, a response surface approach was used for the optimization of enzyme production by SSF. The process variables optimized were incubation time, moisture level, inoculum size and total mineral salt concentration.

\section{MATERIALS AND METHODS}

\section{Materials}

Commercial quality rice husk and brans of rice, wheat, black gram and maize were obtained from a rural market in Vellore, India. These were used as solid substrate in SSF. Until a consistent weight was achieved, the substrates were oven-dried at $70^{\circ} \mathrm{C}$. Glucose oxidase/peroxidase (GODPOD) assay kit used was obtained from Agappe Diagnostics Ltd (India).

\section{Microorganism and maintenance}

The thermophilic fungus, Humicola grisea MTCC 352, was obtained from Microbial Type Culture Collection, Chandigarh, India. The strain was grown on Potato Dextrose Agar (PDA) tubes. The slants were kept at $45^{\circ} \mathrm{C}$ for a 10 -day period. The slants were then stored at $4^{\circ} \mathrm{C}$, before use.

\section{Inoculum preparation}

The cultivation was initiated with conidial suspension $(2 \mathrm{~mL})$, formulated by taking $0.15 \%$ Triton X-100 and added to $250 \mathrm{~mL}$ conical flasks that contained $100 \mathrm{~mL}$ medium (containing $1 \mathrm{~g}$ glucose, $200 \mathrm{mg}$ peptone, 
$50 \mathrm{mg} \mathrm{MgSO}_{4} \cdot 7 \mathrm{H}_{2} \mathrm{O}, 50 \mathrm{mg} \mathrm{CaCl}, 100 \mathrm{mg} \mathrm{K} \mathrm{HPO}_{4}, 200 \mathrm{mg} \mathrm{KH} \mathrm{PO}_{4}$ and $500 \mu \mathrm{L}$ of Vogel's trace elements solution), adjusted to $\mathrm{pH} 5$. A shaking incubator set at $45^{\circ} \mathrm{C}$ and $100 \mathrm{rpm}$ was used to grow the culture for 4 days.

\section{Enzyme production}

Microbial culture using solid substrate was performed in a $250-\mathrm{mL}$ conical flask that contained $5 \mathrm{~g}$ of agricultural waste residue and $5-\mathrm{mL}$ mineral salts solution $\left(\mathrm{MgSO}_{4} \cdot 7 \mathrm{H}_{2} \mathrm{O}, 2 \%\right.$; $\left.\mathrm{KH}_{2} \mathrm{PO}_{4}, 2 \%\right)$. The SSF medium was supplemented with yeast extract and soluble starch (both at, 1\% w/w) as external carbon and nitrogen source, respectively. Prior to sterilization, the moisture content in the medium was altered using distilled water. The fermentation process was started by adding $10 \%$ inoculum $(\mathrm{v} / \mathrm{w})$ as prepared above. To achieve uniformity, the contents of the flask were stirred well before incubation. At stationary conditions, the flasks were incubated for 4 days at $45^{\circ} \mathrm{C}$.

\section{Preparation of crude enzyme}

When the fermentation period ended, the entire solid medium was subjected to treat with $50 \mathrm{~mL}$ distilled water. This was placed in a shaker that was thoroughly agitated at $100 \mathrm{rpm}$ for a 30 -minute period. The suspension was then subjected to filtration using filter paper (Whatman grade 1). The permeate was centrifuged for 10 minutes at a speed of $10,000 \mathrm{rpm}$, leading to the removal of fungal mycelia. The cell-free supernatant was referred to as crude enzyme and was used throughout the experiments.

\section{Glucoamylase assay}

A suitable quantity of crude enzyme was allowed to react with $1 \%$ (w/v) soluble starch solution in $50 \mathrm{mM}$ citrate buffer $\left(\mathrm{pH} \mathrm{5.5)}\right.$, at $60^{\circ} \mathrm{C}$ for the duration of $10 \mathrm{~min}$. The total amount of glucose formed was quantified using Glucose oxidase - peroxidase (GOD-POD) assay kit. A unit of glucoamylase activity is expressed as that quantity of glucoamylase which produces $1 \mu$ mole of glucose from starch (soluble) per minute under assay settings.

\section{Central composite design (CCD) and Response surface methodology}

RSM derived from the CCD of experiments was made used to optimize four significant factors (mineral salt solution concentration, incubation period, initial moisture content and inoculum size) for glucoamylase production in SSF. Mineral salt solution concentration, incubation period, initial moisture content and inoculum size were respectively symbolized as $X_{1}, X_{2}, X_{3}$, and $X_{4}$ (Table 1). The design contained two factorial points 
$(-1$ and +1$)$, two star points $(-2$ and +2$)$ and a middle point $(0)$ to estimate the variability of the process with glucoamylase yield as the response.

Table 1. Ranges of the independent variables used in central composite design.

\begin{tabular}{clrrrrr}
\hline \multirow{2}{*}{ Symbol } & \multicolumn{1}{c}{ Variable } & \multicolumn{5}{c}{ Coded level } \\
\cline { 3 - 7 } & \multicolumn{1}{c}{$\mathbf{- 2}$} & $\mathbf{- 1}$ & $\mathbf{0}$ & $\mathbf{1}$ & $\mathbf{2}$ \\
\hline $\mathrm{X}_{1}$ & $\begin{array}{l}\text { Mineral salt solution concentration } \\
(\% \mathrm{v} / \mathrm{w})\end{array}$ & 20 & 40 & 60 & 80 & 100 \\
$\mathrm{X}_{2}$ & Incubation Period $(\mathrm{h})$ & 48 & 72 & 96 & 120 & 144 \\
$\mathrm{X}_{3}$ & Initial moisture content $(\% \mathrm{v} / \mathrm{w})$ & 100 & 200 & 300 & 400 & 500 \\
$\mathrm{X}_{4}$ & Inoculum size $(\% \mathrm{v} / \mathrm{w})$ & 10 & 15 & 20 & 25 & 30 \\
\hline
\end{tabular}

A total of 31 experiments were performed according to the matrix, based on a 4-factor, 5-level CCD (Table 2). The results obtained from experiments were built into a quadratic expression, as a function of the four factors with coded values and is given in equation 1.

$$
Y=\beta_{0}+\sum \beta_{i} X_{i}+\sum \beta_{i i} X_{i}^{2}+\sum \beta_{i j} X_{i} X_{j}
$$

where $Y$ denotes dependent variable's predicted response (glucoamylase yield), $\beta_{0}$ denotes constant offset term, $\beta_{i}$ denotes linear effect, $\beta_{i j}$ and $\beta_{i i}$ denotes quadratic effect and squared term, respectively. $X_{i}$ and $X_{j}$ denote coded independent variables for statistical designs as per equation 2 .

$$
X=\frac{U-U_{0}}{\Delta U}
$$

where $X$ denotes independent variable's coded value, $U \& U_{0}$ denotes independent variable's real value and real value on center point, respectively. $\Delta U$ denotes value of step change. 


\section{Statistical analysis}

Statistical analysis of the model developed by CCD was analyzed by Analysis of variance (ANOVA) concept, by making use of the statistical software package MINITAB-17.1.0 (MINITAB Inc., PA, USA). The polynomial model was statistically verified by using various parameters like linear regression coefficient $R^{2}, F$-value and absolute average relative deviation (AARD).

\section{RESULTS}

\section{Screening of agricultural waste residue for glucoamylase production}

In the present study, five different substrates, viz., rice bran, wheat bran, rice husk, black gram bran \& maize bran were tried for extracellular glucoamylase production. Glucoamylase yield of solid state fermentation on various agricultural wastes with $50 \%$ of initial moisture is displayed in Figure 1. It was observed that the type of substrates for culturing Humicola grisea played a significant role in the production of glucoamylase. Among the five agricultural substrates studied, the maximum glucoamylase yield was obtained with the medium containing wheat bran. On the other hand, lowest enzyme yield was observed with black gram bran. The substrate suitability for glucoamylase production is as per the following order: wheat bran $>$ maize bran $>$ rice bran $>$ rice husk $>$ black gram bran. Thus, wheat bran was selected as the best source for the production of glucoamylase production in the subsequent experiments.

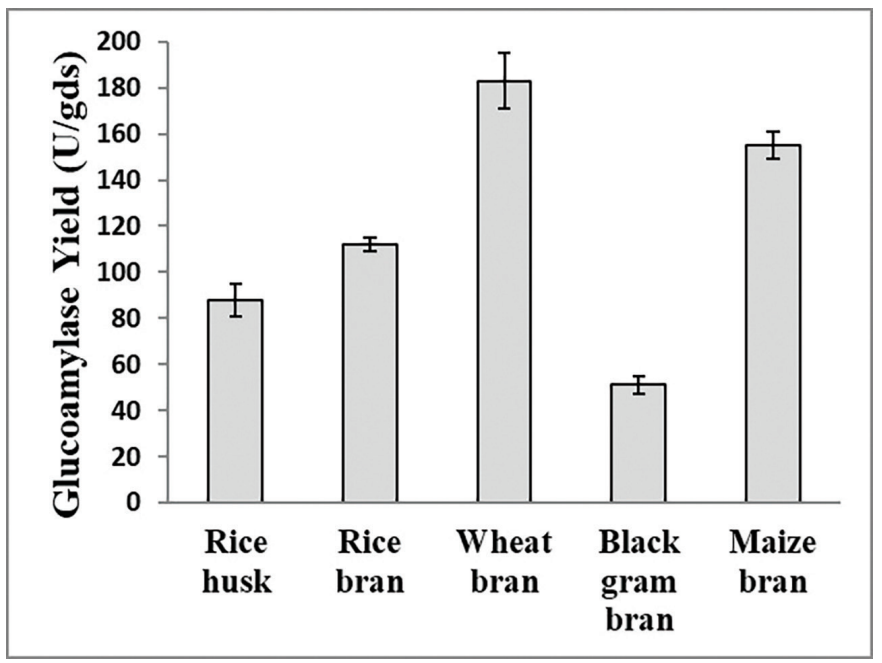

Figure 1. Influence of agricultural waste residues on glucoamylase production. 


\section{Optimization of fermentation parameters by response surface approach}

The response surface methodology using CCD was employed for the determination of the optimum value of the four important parameters (mineral salt solution concentration, incubation period, initial moisture content and inoculum size) for glucoamylase production. A total of 31 experiments were conducted as per the design matrix and the resulting glucoamylase yield is displayed in Table 2 along with the predicted glucoamylase yield.

Table 2. Experimental and predicted responses of the CCD.

\begin{tabular}{|c|c|c|c|c|c|c|}
\hline \multirow{2}{*}{ Trial } & \multicolumn{4}{|c|}{ Coded variable level } & \multicolumn{2}{|c|}{ Glucoamylase yield (U/gds) } \\
\hline & $\mathbf{X}_{1}$ & $\mathbf{X}_{2}$ & $\mathbf{X}_{3}$ & $\mathbf{X}_{4}$ & Observed & Predicted \\
\hline 1 & -1 & 1 & -1 & -1 & 225 & 236 \\
\hline 2 & 0 & 0 & 0 & 2 & 193 & 201 \\
\hline 3 & 1 & -1 & 1 & -1 & 224 & 227 \\
\hline 4 & 1 & 1 & 1 & 1 & 196 & 192 \\
\hline 5 & 0 & 0 & 0 & 0 & 266 & 272 \\
\hline 6 & 0 & 0 & 0 & 0 & 270 & 272 \\
\hline 7 & -1 & -1 & -1 & 1 & 208 & 211 \\
\hline 8 & 1 & -1 & -1 & 1 & 204 & 204 \\
\hline 9 & 0 & 0 & 2 & 0 & 176 & 184 \\
\hline 10 & -1 & -1 & 1 & 1 & 202 & 204 \\
\hline 11 & 0 & 0 & 0 & 0 & 275 & 272 \\
\hline 12 & -1 & 1 & 1 & -1 & 221 & 218 \\
\hline 13 & 0 & 0 & 0 & -2 & 281 & 274 \\
\hline 14 & 0 & 0 & -2 & 0 & 224 & 217 \\
\hline 15 & 1 & -1 & 1 & 1 & 198 & 189 \\
\hline 16 & -1 & -1 & -1 & -1 & 251 & 252 \\
\hline 17 & 0 & 0 & 0 & 0 & 278 & 272 \\
\hline 18 & 0 & 0 & 0 & 0 & 277 & 272 \\
\hline 19 & 0 & 2 & 0 & 0 & 237 & 243 \\
\hline 20 & -1 & -1 & 1 & -1 & 217 & 218 \\
\hline 21 & 1 & -1 & -1 & -1 & 261 & 269 \\
\hline 22 & 0 & 0 & 0 & 0 & 269 & 272 \\
\hline 23 & 0 & 0 & 0 & 0 & 267 & 272 \\
\hline 24 & 2 & 0 & 0 & 0 & 185 & 187 \\
\hline 25 & 1 & 1 & -1 & 1 & 190 & 191 \\
\hline
\end{tabular}


Table 2. Continued.

\begin{tabular}{cccccccc}
\hline \multirow{2}{*}{ Trial } & \multicolumn{4}{c}{ Coded variable level } & & \multicolumn{2}{c}{ Glucoamylase yield (U/gds) } \\
\cline { 2 - 4 } \cline { 7 - 7 } & $\mathbf{X}_{\mathbf{1}}$ & $\mathbf{X}_{\mathbf{2}}$ & $\mathbf{X}_{\mathbf{3}}$ & $\mathbf{X}_{\mathbf{4}}$ & & Observed & Predicted \\
\hline 26 & -2 & 0 & 0 & 0 & & 188 & 186 \\
27 & -1 & 1 & 1 & 1 & & 215 & 209 \\
28 & 1 & 1 & -1 & -1 & & 257 & 252 \\
29 & 0 & -2 & 0 & 0 & & 262 & 256 \\
30 & 1 & 1 & 1 & -1 & & 227 & 226 \\
31 & -1 & 1 & -1 & 1 & & 206 & 200 \\
\hline
\end{tabular}

To explain the production of glucoamylase, the second-order regression model equation in terms of coded values was established and expressed in equation 3.

$$
\begin{aligned}
Y & =271.71+0.25 X_{1}-3.25 X_{2}-8.25 X_{3}-18.33 X_{4}-21.2 X_{1} * X_{1}-5.45 X_{2} * X_{2} \\
& -17.82 X_{3} * X_{3}-8.57 X_{4} * X_{4}-0.37 X_{1} * X_{2}+2 X_{1} * X_{3}-6.13 X_{1} * X_{4} \\
& +4 X_{2} * X_{3}+1.12 X_{2} * X_{4}+6.75 X_{3} * X_{4}
\end{aligned}
$$

The values of the analysis of variance (ANOVA) for the model are presented in Table 3.

Table 3. ANOVA for the quadratic model.

\begin{tabular}{lcrcrc}
\hline Variables & $\begin{array}{c}\text { Coefficient } \\
\text { estimate }\end{array}$ & $\begin{array}{r}\text { Sum of } \\
\text { squares }\end{array}$ & $\begin{array}{c}\text { Degrees of } \\
\text { freedom }\end{array}$ & F value & P value \\
\hline Model & 271.71 & $32,215.8$ & 14 & 43.04 & $<0.0001$ \\
Linear & & $9,955.2$ & 4 & 46.56 & $<0.0001$ \\
$\mathrm{X}_{1}$ & 0.25 & 1.5 & 1 & 0.03 & 0.869 \\
$\mathrm{X}_{2}$ & -3.25 & 253.5 & 1 & 4.74 & 0.045 \\
$\mathrm{X}_{3}$ & -8.25 & $1,633.5$ & 1 & 30.56 & $<0.0001$ \\
$\mathrm{X}_{4}$ & -18.33 & $8,066.7$ & 1 & 150.89 & $<0.0001$ \\
Square & & $20,588.8$ & 4 & 96.28 & $<0.0001$ \\
$\mathrm{X}_{1^{*}} \mathrm{X}_{1}$ & -21.20 & $12,851.3$ & 1 & 240.4 & $<0.0001$ \\
$\mathrm{X}_{2^{*}} \mathrm{X}_{2}$ & -5.45 & 849.2 & 1 & 15.88 & 0.001 \\
$\mathrm{X}_{3^{*}} \mathrm{X}_{3}$ & -17.82 & $9,085.1$ & 1 & 169.95 & $<0.0001$ \\
$\mathrm{X}_{4^{*}} \mathrm{X}_{4}$ & -8.57 & $2,102.4$ & 1 & 39.33 & $<0.0001$
\end{tabular}


Table 3. Continued

\begin{tabular}{lccccc}
\hline \multicolumn{1}{c}{ Variables } & $\begin{array}{c}\text { Coefficient } \\
\text { estimate }\end{array}$ & $\begin{array}{c}\text { Sum of } \\
\text { squares }\end{array}$ & $\begin{array}{c}\text { Degrees of } \\
\text { freedom }\end{array}$ & F value & P value \\
\hline 2-Way Interaction & & $1,671.8$ & 6 & 5.21 & 0.004 \\
$\mathrm{X}_{1^{*}} \mathrm{X}_{2}$ & -0.37 & 2.2 & 1 & 0.04 & 0.84 \\
$\mathrm{X}_{1^{*}} \mathrm{X}_{3}$ & -2.00 & 64 & 1 & 1.2 & 0.29 \\
$\mathrm{X}_{1^{*}} \mathrm{X}_{4}$ & -6.13 & 600.2 & 1 & 11.23 & 0.004 \\
$\mathrm{X}_{2^{*}} \mathrm{X}_{3}$ & 4.00 & 256 & 1 & 4.79 & 0.044 \\
$\mathrm{X}_{2^{*}} \mathrm{X}_{4}$ & 1.12 & 20.2 & 1 & 0.38 & 0.547 \\
$\mathrm{X}_{3^{*}} \mathrm{X}_{4}$ & 6.75 & 729 & 1 & 13.64 & 0.002 \\
Residual & & 855.3 & 16 & & \\
Lack of Fit & & 711.9 & 10 & 2.98 & 0.097 \\
Pure Error & & 143.4 & 6 & 43.04 & $<0.0001$ \\
Total & & $3,3071.1$ & 30 & 46.56 & $<0.0001$ \\
\hline
\end{tabular}

The model resulted in F-value of 43.04 and coefficient of determination $\left(R^{2}\right): 0.9741$. The lack of fit $F$ value 2.98. The $P$ values were lesser than 0.05 for the linear terms, square effects and interactive effects of mineral salt solution concentration and inoculum size, incubation period and inoculum size as well as initial moisture content and inoculum size. The interaction between the inoculum size and other factors is insignificant for the model obtained. It is clear from the results that the size of inoculum has an independent influence, without interacting with other factors. The $P$ value for the lack of fit was found to be 0.097 . For the current system, an AARD of $1.98 \%$ was obtained. Figure 2 displays normal distribution of data as a linear trend, which is the indicator that glucoamylase yield obtained from experiments fits the model equation. 


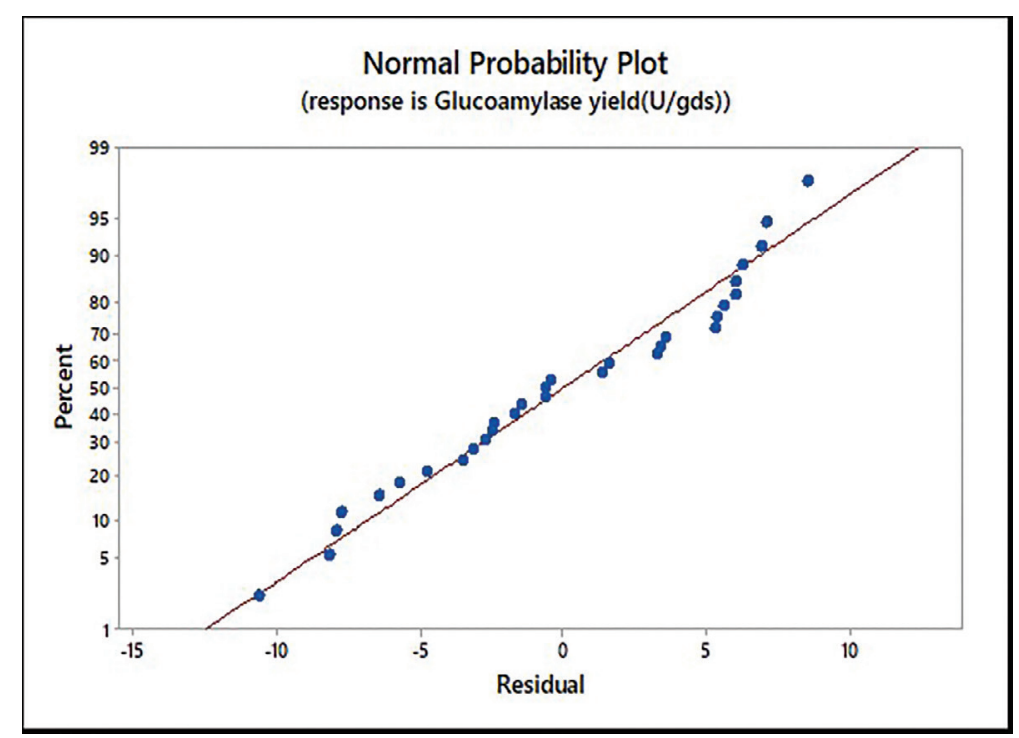

Figure 2. Normal probability plot of glucoamylase production.

In order to visualize the interaction effects between each variable on glucoamylase production, two-dimensional contour plots are shown graphically in Figure 3. The interaction effects between two factors are shown with the other two variables kept constant at their center value. It is clear from the plots that there is a change in glucoamylase production with respect to the low or high levels of the factors. The contour plot between the factors, incubation period \& initial moisture content indicates the significant interaction effect and an increase in glucoamylase production at their higher values. The interaction between mineral salt solution concentration \& incubation period and mineral salt solution concentration \& initial moisture content shows a negative effect (decrease in glucoamylase production at higher values). The same phenomena are numerically shown in Table 3.

The response optimizer tool in MINITAB was used to get a solution for the obtained second-order model equation. The optimum levels of each variable in uncoded units were as follows: mineral salt solution concentration $=$ $65 \%(\mathrm{v} / \mathrm{w})$, incubation period $=80 \mathrm{~h}$, initial moisture content $=240 \%(\mathrm{v} / \mathrm{w})$ and inoculum size $=13 \%(\mathrm{v} / \mathrm{w})$, all of which were located within the experimental range. The predicted glucoamylase yield on wheat bran at the optimum levels of the factors was $288 \mathrm{U} / \mathrm{gds}$. Experiments were performed in triplicates at the optimized values to validate the regression model. Under the optimized conditions, the average of observed experimental values was $282 \pm 11 \mathrm{U} / \mathrm{gds}$. 

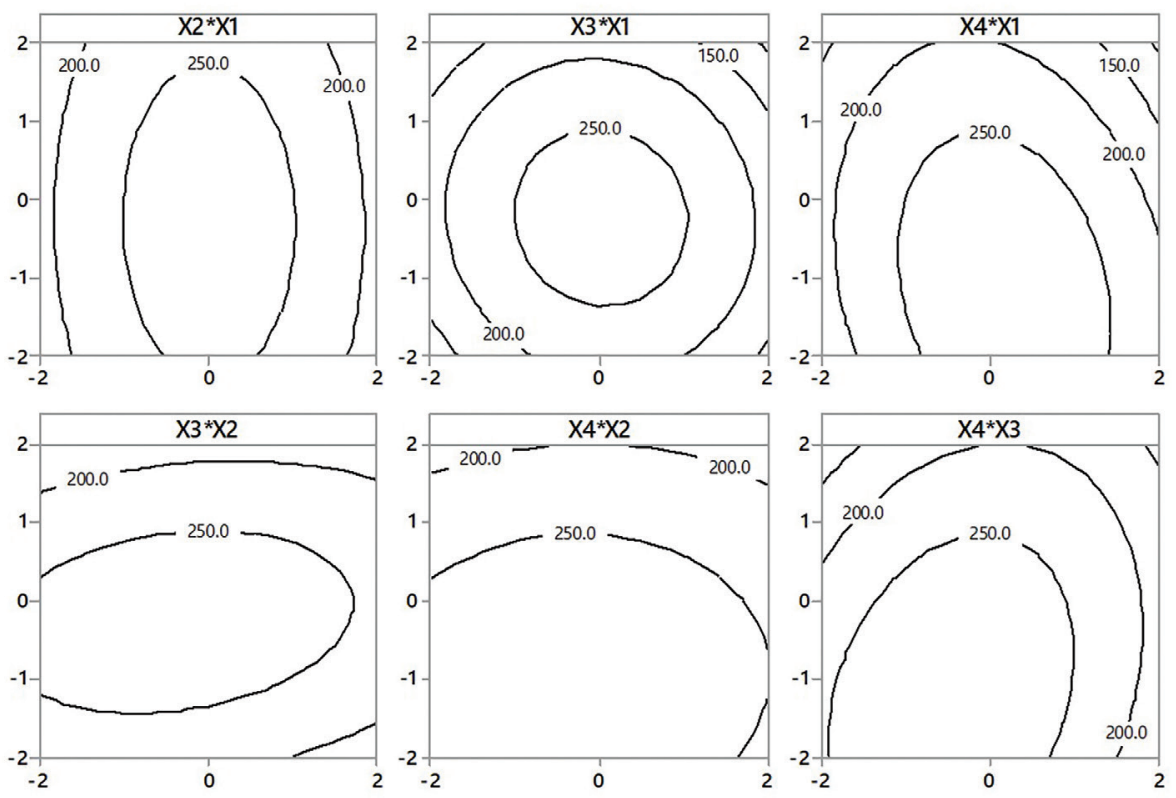

Figure 3. Two-dimensional contour plots for glucoamylase yield (U/gds) $\left(\mathrm{X}_{1}\right.$ - Mineral salt solution concentration; $\mathrm{X}_{2}$ - Incubation period; $\mathrm{X}_{3}$ - Initial moisture content; $\mathrm{X}_{4}$ - Inoculum size).

\section{DISCUSSION}

The production of extracellular glucoamylase by Humicola grisea MTCC 352 was investigated with numerous readily available agricultural waste residues. The screening is aimed towards the selection of better solid substrate, which is a crucial step in the solid state cultivation for the production of desired product. Wheat bran, as the most promising solid substrate for glucoamylase production, has been reported by several researchers (Ellaiah et al., 2002; Anto et al., 2006; Bhatti et al., 2007).

The second-order model obtained from the response surface analysis can be sensibly used, as the difference between the obtained and theoretical yield is meagre. The ANOVA results showed higher model $F$ value (43.04) suggests that the second-order model equation obtained was significant. The significance of the second-order model can also be confirmed as results of lack of fit $F$ value. The lower $F$ value of lack of fit (2.98) compared with higher $F$ values of the model suggest the model is significant by means of non-significance lack of fit 
(Montgomery, 2005). The significance of the second-order regression model can be similarly established with higher coefficient of determination $\left(R^{2}\right): 0.9741$ indicates the extent of correlation between measured glucoamylase yield and model equation. Similarly, the significance of model terms can be established for $P$ values lesser than 0.05 (Montgomery, 2005). The linearity of the normal probability plot confirms all major assumptions of the model viz., distribution of errors, same errors of variance, randomization and mean error stand validated. The AARD explains the extent to which the predicted values differ from the experimental values and a lesser value $(<5 \%)$ is preferred for a good model (Raja and Murty, 2012). For the current model the AARD value of $1.98 \%$ confirms its adequacy.

Contour plots illustrate the substrate to mineral salt solution concentration and initial moisture content have not supported a higher glucoamylase production at their maximum and minimum levels. Lower mineral salt solution concentration causes insufficient nutrient availability, whereas increase in salt concentration was found to inhibit glucoamylase activity (Kunamneni et al., 2005). The resistance for oxygen transport continuously increases with the decrease in porosity of the agricultural residue resulting from an increase in the moisture level of the solid bed. On the other hand, a decrease in moisture content results in lower solubility of nutrients and reduced availability at microbial surface as well as less swelling of the bed (Ellaiah et al., 2002). A similar effect was observed with incubation period. The incubation period for obtaining the maximum glucoamylase yield is decided based on characteristics of the microorganism and is dependent on the product formation rate. The high inoculum size resulted in the high glucose supplementation to the fungus leading to the decrease in glucoamylase yield.

The good correlation between the observed and predicted glucoamylase yield further confirms the adequacy of the model. In addition to this, the optimized glucoamylase yield was found to be higher than the available literature value for the various microorganisms grown on wheat bran medium such as Aspergillus awamori [13.7 U/gds] (Bertolin et al., 2003), Colletotrichum sp. [61 U/gds] (Prajapati, et al., 2013), Fusarium solani [61.35 U/gds] (Bhatti et al., 2007), Aspergillus awamori [48 U/gds] (Du et al., 2008) and Aspergillus sp [247 U/gds] (Ellaiah et al., 2002).

\section{CONCLUSION}

Initial screening study revealed that the type of agricultural waste residue used significantly influences glucoamylase production. Among the tested sources, wheat bran was the best agricultural residue for the glucoamylase production in solid state fermentation. The current study demonstrates the 
use of response surface approach for optimization of significant fermentation factors which resulted in enhanced glucoamylase yield. The values of the four parameters were optimized by employing CCD (mineral salt solution concentration: $65 \%(\mathrm{v} / \mathrm{w})$, incubation period: $80 \mathrm{~h}$, initial moisture content: $240 \%(\mathrm{v} / \mathrm{w})$ and inoculum size: $13 \%(\mathrm{v} / \mathrm{w}))$. The proposed second-order model was validated as the difference between the obtained experimental glucoamylase yield of $282 \pm 11 \mathrm{U} / \mathrm{gds}$ and the predicted glucoamylase yield of $288 \mathrm{U} / \mathrm{gds}$, which was meagre. Thus, the optimized conditions for the solid state fermentation found out in the current study might reduce the overall cost of the production and provides a basis for further studies on a large scale.

\section{ACKNOWLEDGEMENTS}

The authors gratefully acknowledge the Department of Biotechnology, MIT, Manipal Academy of Higher Education for providing the facilities to carry out the research work.

\section{REFERENCES}

Anto, H., Trivedi, U.B., and Patel, K.C. 2006. Glucoamylase production by solid-state fermentation using rice flake manufacturing waste products as substrate. Bioresource Technology. 97(10): 1161-1166. https://doi. org/10.1016/j.biortech.2005.05.007

Babu, K.R., and Satyanarayana, T. 1995. $\alpha$-Amylase production by thermophilic Bacillus coagulans in solid state fermentation. Process Biochemistry. 30(4): 305-309. https://doi.org/10.1016/0032-9592(95)87038-5

Balkan, B., and Ertan, F. 2007. Production of $\alpha$-Amylase from Penicillium chrysogenum under solid-state fermentation by using some agricultural by-products. Food Technology and Biotechnology. 45(4): 439-442.

Baysal, Z., Uyar, F., and Aytekin, Ç. 2003. Solid state fermentation for production of $\alpha$-amylase by a thermotolerant Bacillus subtilis from hot-spring water. Process Biochemistry. 38(12): 1665-1668. https://doi.org/10.1016/ S0032-9592(02)00150-4

Bertolin, T.E., Schmidell, W., Maiorano, A.E., Casara, J., and Costa, J.A. 2003. Influence of carbon, nitrogen and phosphorous sources on glucoamylase production by Aspergillus awamori in solid state fermentation. Zeitschrift für Naturforschung C. 58(9-10): 708-712. https://doi.org/10.1515/znc2003-9-1020 
Bhargav, S., Panda, B.P., Ali, M., and Javed, S. 2008. Solid-state fermentation: an overview. Chemical and Biochemical Engineering Quarterly. 22(1): 49-70.

Bhatti, H.N., Rashid, M.H., Nawaz, R., Asgher, M., Perveen, R., and Jabbar, A. 2007. Optimization of media for enhanced glucoamylase production in solid-state fermentation by Fusarium solani. Food Technology and Biotechnology. 45(1): 51-56.

Campos, L., and Felix, C.R. 1995. Purification and characterization of a glucoamylase from Humicola grisea. Applied and Environmental Microbiology. 61(6): 2436-2438.

Couto, S.R., and Sanromán, M.A. 2006. Application of solid-state fermentation to food industry - a review. Journal of Food Engineering. 76(3): 291302. https://doi.org/10.1016/j.jfoodeng.2005.05.022

Du, C., Lin, S.K.C., Koutinas, A., Wang, R., Dorado, P., and Webb, C. 2008. A wheat biorefining strategy based on solid-state fermentation for fermentative production of succinic acid. Bioresource Technology. 99(17): 8310-8315. https://doi.org/10.1016/j.biortech.2008.03.019

Ellaiah, P., Adinarayana, K., Bhavani, Y., Padmaja, P., and Srinivasulu, B. 2002. Optimization of process parameters for glucoamylase production under solid state fermentation by a newly isolated Aspergillus species. Process Biochemistry. 38(4): 615-620. https://doi.org/10.1016/S0032-9592(02) 00188-7

James, J.A., and Lee, B.H. 1996. Characterization of glucoamylase from Lactobacillus amylovorus ATCC 33621. Biotechnology Letters. 18(12): 1401-1406. https://doi.org/10.1007/BF00129343

Kumar, S., and Satyanarayana, T. 2004. Statistical optimization of a thermostable and neutral glucoamylase production by a thermophilic mold Thermoтисо indicae-seudaticae in solid-state fermentation. World Journal of Microbiology and Biotechnology. 20(9): 895-902. https://doi. org/10.1007/s11274-004-2891-z

Kunamneni, A., Permaul, K., and Singh, S. 2005. Amylase production in solid state fermentation by the thermophilic fungus Thermomyces lanuginsus. Journal of Bioscience and Bioengineering. 100(2): 168-171. https://doi. org/10.1263/jbb.100.168

Lam, W.C., Pleissner, D., and Lin, C.S.K. 2013. Production of fungal glucoamylase for glucose production from food waste. Biomolecules. 3(3): 651661. https://doi.org/10.3390/biom3030651

Melikoglu, M., Lin, C.S.K., and Webb, C. 2013. Stepwise optimisation of enzyme production in solid state fermentation of waste bread pieces. Food and Bioproducts Processing. 91(4): 638-646. https://doi.org/10.1016/j. fbp.2013.04.008 
Montgomery, D.C. 2005. Design and analysis of experiments. John Wiley \& Sons.

Negi, S., Gupta, S., and Banerjee, R. 2011. Extraction and purification of glucoamylase and protease produced by Aspergillus awamori in a single-stage fermentation. Food Technology and Biotechnology. 49(3): 310-315.

Pandey, A. 2003 . Solid-state fermentation. Biochemical Engineering Journal. 13(2): 81-84. https://doi.org/10.1016/S1369-703X(02)00121-3

Prajapati, V.S., Trivedi, U.B., and Patel, K.C. 2013. Optimization of glucoamylase production by Colletotrichum $\mathrm{sp}$. KCP1 using statistical methodology. Food Science and Biotechnology. 22(1): 31-38. https://doi. org/10.1007/s10068-013-0005-0

Raja, S., and Murty, V.R. 2012. Development and evaluation of environmentally benign aqueous two phase systems for the recovery of proteins from tannery waste water. ISRN Chemical Engineering. 2012: 1-9. http://dx. doi.org/10.5402/2012/290471

Ramachandran, S., Patel, A.K., Nampoothiri, K.M., Francis, F., Nagy, V., Szakacs, G., and Pandey, A. 2004. Coconut oil cake-a potential raw material for the production of $\alpha$-amylase. Bioresource Technology. 93(2): 169-174. https://doi.org/10.1016/j.biortech.2003.10.021

Ramesh, V., and Murty, V.R. 2014. Sequential statistical optimization of media components for the production of glucoamylase by thermophilic fungus Humicola grisea MTCC 352. Enzyme Research. 2014: 1-9. https://doi. org/10.1155/2014/317940

Ramesh, V., and Murty, V.R. 2015. Partitioning of thermostable glucoamylase in polyethyleneglycol/salt aqueous two-phase system. Bioresources and Bioprocessing. 2(1): 1-8. https://doi.org/10.1186/s40643-015-0056-6

Selvakumar, P., Ashakumary, L., and Pandey, A. 1998. Biosynthesis of glucoamylase from Aspergillus niger by solid-state fermentation using tea waste as the basis of a solid substrate. Bioresource Technology. 65(1): 83-85. https://doi.org/10.1016/S0960-8524(98)00012-1

Singh, H., and Soni, S.K. 2001. Production of starch-gel digesting amyloglucosidase by Aspergillus oryzae HS-3 in solid state fermentation. Process Biochemistry. 37(5): 453-459. https://doi.org/10.1016/S00329592(01)00238-2

Te Biesebeke, R., Record, E., Van Biezen, N., Heerikhuisen, M., Franken, A., Punt, P.J., and Van Den Hondel, C.A.M.J.J. 2005. Branching mutants of Aspergillus oryzae with improved amylase and protease production on solid substrates. Applied Microbiology and Biotechnology. 69(1): 44-50. https://doi.org/10.1007/s00253-005-1968-4 
Tosi, L.R.O., Terenzi, H.F., and Jorge, J.A. 1993. Purification and characterization of an extracellular glucoamylase from the thermophilic fungus Humicola grisea var. thermoidea. Canadian Journal of Microbiology. 39(9): 846-852. https://doi.org/10.1139/m93-126

Wang, R., Godoy, L.C., Shaarani, S.M., Melikoglu, M., Koutinas, A., and Webb, C. 2009. Improving wheat flour hydrolysis by an enzyme mixture from solid state fungal fermentation. Enzyme and Microbial Technology. 44(4): 223-228. https://doi.org/10.1016/j.enzmictec.2008.10.002 